\title{
Optimal Operation of Alternating Activated Sludge Processes
}

\author{
M. Fikar, B. Chachuat, M. A. Latifi ${ }^{\dagger}$ \\ Laboratoire des Sciences du Génie Chimique, CNRS-ENSIC, \\ B.P. 451, 1 rue Grandville, 54001 Nancy Cedex, France, \\ Tel. +33 (0)3 831752 34, Fax. +33 (0)3 831753 26, \\ e-mail: latifi@ensic.u-nancy.fr
}

\begin{abstract}
The study presents dynamic optimisation of a small size single basin wastewater treatment plant. The objectives are to determine an optimal sequence of aeration/nonaeration times so that for a typical diurnal pattern of disturbances, the effluent constraints are respected, the plant remains in periodical steady state, and energy consumption is minimised.

Based on the optimal state trajectories results, two simple feedback rules are proposed. Simulation results with these rules show very satisfactory control performance.
\end{abstract}

Keywords: wastewater treatment, activated sludge process, dynamic optimisation.

\section{Nomenclature}

\section{Roman symbols}

ASM1 - Activated Sludge Model No. 1

ASP - Activated Sludge Process

BOD - Biochemical Oxygen Demand $\left(\mathrm{mg} \mathrm{L}^{-1}\right)$

COD - chemical oxygen demand $\left(\mathrm{mg} \mathrm{L}^{-1}\right)$

\footnotetext{
*on leave from: Department of Information Engineering and Process Control, CHTF STU, Radlinského 9, 81237 Bratislava, Slovakia, Tel :+421 (0)2 59325 354, Fax :+421 (0)2 524964 69, e-mail : fikar@cvt.stuba.sk

${ }^{\dagger}$ Corresponding author
} 
CVP - Control Vector Parameterisation

$\boldsymbol{f}$ - vector of right sides of differential equations $(-)$

IVP - Initial Value Problem

$J$ - performance index $(-)$

$k_{L} a$ - oxygen transfer coefficient $\left(\mathrm{h}^{-1}\right)$

$N_{c}$ - number of cycles $(-)$

NLP - Non-linear Programming

OC - Orthogonal Collocation

$\boldsymbol{p}$ - parameter vector $(-)$

$\mathcal{P}$ - nominal power of the turbines $(\mathrm{kWh})$

p.e. - population-equivalent

$Q$ - flowrate $\left(\mathrm{m}^{3} \mathrm{day}^{-1}\right)$

$r_{i}$ - apparent reaction rate of a component $i\left(\mathrm{mg} \mathrm{L}^{-1}\right.$ day $\left.^{-1}\right)$

$S_{\text {I }}$ - soluble inert COD concentration $\left(\mathrm{mg} \mathrm{L}^{-1}\right)$

$S_{\mathrm{ND}}$ - soluble organic nitrogen concentration $\left(\mathrm{mg} \mathrm{L}^{-1}\right)$

$S_{\mathrm{NH}}-$ ammonium concentration $\left(\mathrm{mg} \mathrm{L}^{-1}\right)$

$S_{\mathrm{NO}}-$ nitrate and nitrite nitrogen concentration $\left(\mathrm{mg} \mathrm{L}^{-1}\right)$

$S_{\mathrm{O}}$ - dissolved oxygen concentration $\left(\mathrm{mg} \mathrm{L}^{-1}\right)$

$S_{\mathrm{S}}$ - readily biodegradable COD concentration $\left(\mathrm{mg} \mathrm{L}^{-1}\right)$

SS - suspended solids $\left(\mathrm{mg} \mathrm{L}^{-1}\right)$

$T$ - optimisation horizon (day)

$\Delta t_{i}-$ aeration/non-aeration time (s)

$\mathrm{TN}$ - total nitrogen $\left(\mathrm{mg} \mathrm{L}^{-1}\right)$

$u_{b}$ - state of turbines - on $(1) /$ off(0) $(-)$

$\boldsymbol{u}$ - control vector $(-)$

$V^{b r}$ - bioreactor volume $\left(\mathrm{m}^{3}\right)$ 
WWTP - Wastewater Treatment Plant

$\boldsymbol{x}$ - state vector $(-)$

$X_{\mathrm{B}, \mathrm{A}}$ - autotrophic biomass concentration $\left(\mathrm{mg} \mathrm{L}^{-1}\right)$

$X_{\mathrm{B}, \mathrm{H}}$ - heterotrophic biomass concentration $\left(\mathrm{mg} \mathrm{L}^{-1}\right)$

$X_{\mathrm{I}}-$ particulate inert COD concentration $\left(\mathrm{mg} \mathrm{L}^{-1}\right)$

$X_{\mathrm{ND}}$ - particulate organic nitrogen concentration $\left(\mathrm{mg} \mathrm{L}^{-1}\right)$

$X_{\mathrm{S}}$ - slowly biodegradable COD concentration $\left(\mathrm{mg} \mathrm{L}^{-1}\right)$

\section{Greek letters}

$\tau_{\mathrm{COD}}$ - influent COD concentration variation $(-)$

$\tau_{Q}-$ influent flowrate variation $(-)$

\section{Subscripts and superscripts}
in - influent
$\max$ - maximum value
rs - recycled sludge
w - excess sludge 


\section{Introduction}

A widely used system for biological wastewater treatment is the activated sludge process (ASP). The removal of nitrogen $(\mathrm{N})$ requires two biological processes : nitrification and denitrification. The former takes place under aerobic conditions, whereas the latter requires anoxic environment. For small size plants, i.e. less than 20,000 p.e. (population equivalent), the two processes are very often carried out in a single basin using surface turbines. The nitrification process (respectively denitrification process) is realised by simply switching the turbines on (respectively off).

Among the issues to be addressed in order to improve the functioning of small size wastewater plants, the effluent quality and the total operation costs are important. Of course these issues are not independent since the pollution reduction generally involves additional costs (investment, operation, ...). The choice of the aforementioned issues is motivated below:

- Effluent quality: During the last decade, a stricter European Union (EU) directive (91/271 "Urban wastewater") came out and fixed the maximum pollutant concentrations allowed in the effluent of small size wastewater treatment plants. For example, for the most restrictive component, i.e. total nitrogen $(\mathrm{TN})$, the maximum concentration is fixed at $10 \mathrm{mg} / \mathrm{l}$.

- Operation costs: The main component of total operation costs of small size wastewater plants is constituted by the energy dissipated by the system of aeration (turbines) (Vasel, 1988). Oxygen control is therefore of great importance since the decrease of the total period of aeration reduces significantly the operation costs.

The main challenge of the control of activated sludge processes is disturbances rejection. The objective is to avoid excessive aeration and to maximise the conversion rates of the biological processes. The most important source of disturbances is the influent. Its characteristics are large diurnal variations both in flowrate and composition (the result of characteristic life patterns of households). Even if the large reactor volume dampens this diurnal cycle, just by dilution, there remains a significant task for active control. The other important sources of disturbances are rain/storm events that may cause serious overloading incidents or in winter time when the growth rate of biomass is severely inhibited by low temperature.

Control of the ASP has been the subject of a large number of research studies. More control oriented are for example the works of Kim et al. (2000) that use simplified linearised model with aeration time as the manipulated variable, Qin et al. (1997) have employed interpolating Model Predictive Control, or Lindberg (1998) has used linear multivariable LQ control.

The studies that investigate the problem from the process point of view include for example the works of Isaacs (Isaacs, 1997, 1996; Zhao et al., 1995, 1994b). A comparison of several control strategies has been investigated in Lukasse et al. (1999); Potter et al. (1996); Debusscher et al. (1999). 
The aim of this work is to determine an optimal duration of the aeration and nonaeration sequences which will minimise the operation costs as well as satisfy the constraints specified by the EU directives. Based on the analysis of the optimal operational policy, simple feedback rules will be formulated.

The rest of the paper is organised as follows. Section 2 introduces the dynamic model considered. Section 3 defines the optimisation problem, discusses the choice of the control variables, and specifies control and state constraints. Main results are presented in Section 4 where a periodic stationary regime is found. Finally, Section 5 concludes the paper.

\section{Wastewater Treatment Plant Model}

\section{$2.1 \quad$ Process}

The process considered is a real small-size treatment plant which is designed for 15, 000 p.e. It consists of a unique aeration tank $\left(V^{\mathrm{br}}=2,050 \mathrm{~m}^{3}\right)$ equipped with mechanical surface aerators (turbines) which provide oxygen $\left(\mathcal{P}=30 \mathrm{~kW}, k_{L} a=4.5 \mathrm{~h}^{-1}\right)$ and mix the incoming wastewater with biomass (Fig. 1). The settler is a cylindrical tank where the solids are either recirculated to the aeration tank $\left(Q^{\mathrm{rs}}=7,600 \mathrm{~m}^{3} /\right.$ day $)$ or extracted from the system $\left(Q^{\mathrm{w}}=75 \mathrm{~m}^{3} /\right.$ day $)$.

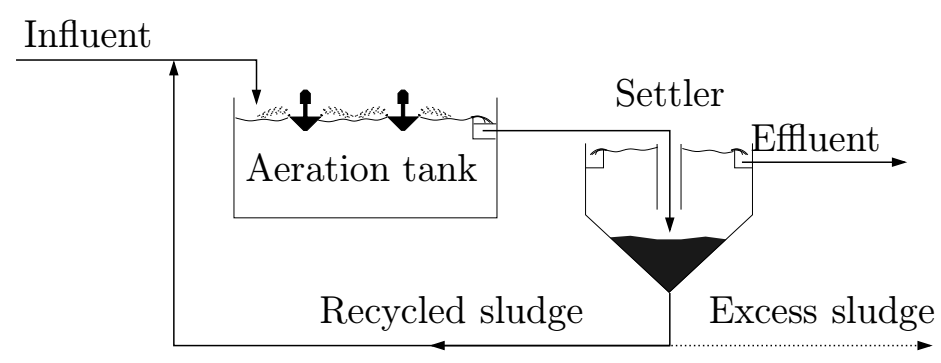

Figure 1: Typical small-size activated sludge treatment plant.

The influent average flow $Q^{\text {in }}$ is about $3,050 \mathrm{~m}^{3} /$ day and average organic COD ${ }^{\text {in }}$ and total nitrogen $\mathrm{TN}^{\text {in }}$ loads are $343 \mathrm{mg} / \mathrm{L}$ and $33 \mathrm{mg} / \mathrm{L}$, respectively (after primary treatment). The daily variations of dry weather conditions are based on measured data from the plant. It is accounted for by defining weighting functions for both influent flowrate and organic load variations, $\tau_{Q}(t)$ and $\tau_{\mathrm{COD}}(t)$ (Fig. 2).

The average wastewater composition is shown in Table 1. The fractions $f$ are related to the state variables presented in Table 2 and defined as the ratio between the corresponding concentration and $\mathrm{COD}^{\text {in }}$ or $\mathrm{TN}^{\text {in }}$. 


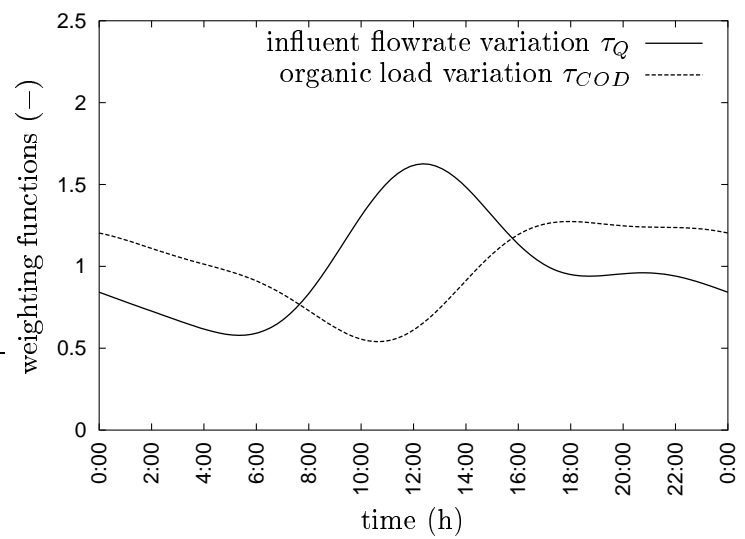

Figure 2: Influent flowrate and organic load variations.

Table 1: Average inlet composition

\begin{tabular}{|c|c|c|c|}
\hline \multicolumn{2}{|c|}{$\mathrm{COD}^{\text {in }}$ fractions } & \multicolumn{2}{|c|}{$\mathrm{TN}^{\text {in }}$ fractions } \\
\hline$f_{\mathrm{SI}}$ & $5 \%$ & $f_{\mathrm{SNH}}$ & $66 \%$ \\
\hline$f_{\mathrm{SS}}$ & $35 \%$ & $f_{\mathrm{SNO}}$ & $0 \%$ \\
\hline$f_{\mathrm{XI}}$ & $10 \%$ & $f_{\mathrm{SND}}$ & $2 \%$ \\
\hline$f_{\mathrm{XS}}$ & $35 \%$ & $f_{\mathrm{XND}}$ & $32 \%$ \\
\hline$f_{\mathrm{XBH}}$ & $15 \%$ & & \\
\hline$f_{\mathrm{XBA}}$ & $0 \%$ & & \\
\hline
\end{tabular}




\section{$2.2 \quad$ Model}

The model used in this the work is based on the Activated Sludge Model No.1 (ASM 1) by Henze et al. (1987). This is the most popular mathematical description of the biochemical processes in the reactors for nitrogen and chemical oxygen demand (COD) removal. It was adopted with two modifications: (i) the state variable describing the total alkalinity is not included, and (ii) inert particulate material from influent and from biomass decay are combined into a single variable $\left(X_{\mathrm{I}}\right)$ since they are of minor interest. The resulting biodegradation model consists of 11 state variables (Table 2) and 20 parameters. The kinetic and stoichiometric parameter values considered are those defined for the simulation benchmark (Alex et al., 1999). The complete set of equations, parameters values, and influent conditions can be found on the European COST action 624 website (http://www.ensic.u-nancy.fr/COSTWWTP) as well as from the authors.

Table 2: Model state variables

\begin{aligned} & \hline 1. Inert soluble organic matter, $S_{\mathrm{I}}\left[\mathrm{gCOD} \mathrm{m}^{-3}\right] \\ &$ 2. Readily biodegradable substrate, $S_{\mathrm{S}}\left[\mathrm{gCOD} \mathrm{m}^{-3}\right] \\ &$ 3. Inert particulate organic matter and products, $X_{\mathrm{I}}\left[\mathrm{gCOD} \mathrm{m}^{-3}\right] \\ &$ 4. Slowly biodegradable substrate, $X_{\mathrm{S}}\left[\mathrm{gCOD} \mathrm{m}^{-3}\right] \\ &$ 5. Active heterotrophic biomass, $X_{\mathrm{B}, \mathrm{H}}\left[\mathrm{gCOD} \mathrm{m}^{-3}\right] \\ &$ 6. Active autotrophic biomass, $X_{\mathrm{B}, \mathrm{A}}\left[\mathrm{gCOD} \mathrm{m}^{-3}\right] \\ &$ 7. Nitrate and nitrite nitrogen, $S_{\mathrm{NO}}\left[\mathrm{gN} \mathrm{m}^{-3}\right] \\ &$ 8. Ammonium nitrogen, $S_{\mathrm{NH}}\left[\mathrm{gN} \mathrm{m}^{-3}\right] \\ &$ 9. Soluble biodegradable organic nitrogen, $S_{\mathrm{ND}}\left[\mathrm{gN} \mathrm{m}^{-3}\right] \\ &$ 10. Particulate biodegradable organic nitrogen, $X_{\mathrm{ND}}\left[\mathrm{gN} \mathrm{m}^{-3}\right] \\ &$ 11. Dissolved oxygen, $S_{\mathrm{O}}\left[\mathrm{gO}_{2} \mathrm{~m}^{-3}\right] \\ &$\hline\end{aligned}

The model assumptions are as follows:

- the reactor is well mixed,

- perfect separation of liquid and solid phases in the settler,

- the sum of all settler flowrates equals the settler influent flowrate.

The model of the system involves 11 state variables $\left(S_{\mathrm{I}} S_{\mathrm{S}} X_{\mathrm{I}} X_{\mathrm{S}} X_{\mathrm{B}, \mathrm{H}} X_{\mathrm{B}, \mathrm{A}} S_{\mathrm{NO}} S_{\mathrm{NH}}\right.$ $\left.S_{\mathrm{ND}} X_{\mathrm{ND}} S_{\mathrm{O}}\right)^{T}$ with the associated initial conditions given in Table 3.

The model differential equations can be stated as

$$
\dot{\boldsymbol{x}}=\boldsymbol{f}(\boldsymbol{x})
$$

where $\boldsymbol{f}$ are right hand sides of the differential equations given by: 
Table 3: Initial concentrations in the aeration tank

\begin{tabular}{cccccccccccc}
\cline { 2 - 7 } & $S_{\mathrm{I}}$ & $S_{\mathrm{S}}$ & $X_{\mathrm{I}}$ & $X_{\mathrm{S}}$ & $X_{\mathrm{B}, \mathrm{H}}$ & $X_{\mathrm{B}, \mathrm{A}}$ & $S_{\mathrm{NO}}$ & $S_{\mathrm{NH}}$ & $S_{\mathrm{ND}}$ & $X_{\mathrm{ND}}$ & $S_{\mathrm{O}}$ \\
\hline Conc. $(\mathrm{mg} / \mathrm{L})$ & 17.98 & 2.27 & 2120.15 & 79.55 & 2238.65 & 115.18 & 0.02 & 9.70 & 0.14 & 6.29 & 0.00 \\
\hline
\end{tabular}

- For soluble components $(i=1,2,7,8,9)$ :

$$
f_{i}(\boldsymbol{x})=\frac{Q^{\text {in }}}{V^{\text {br }}}\left(x_{i}^{\text {in }}-x_{i}\right)+r_{i}(\boldsymbol{x})
$$

- For particulate components $(i=3,4,5,6,10)$ :

$$
f_{i}(\boldsymbol{x})=\frac{1}{V^{\mathrm{br}}}\left[Q^{\text {in }}\left(x_{i}^{\mathrm{in}}-x_{i}\right)+Q^{\mathrm{rs}} \frac{Q^{\mathrm{in}}-Q^{\mathrm{w}}}{Q^{\mathrm{rs}}+Q^{\mathrm{w}}} x_{i}\right]+r_{i}(\boldsymbol{x})
$$

- For dissolved oxygen concentration $(i=11)$ :

$$
f_{11}(\boldsymbol{x})=\frac{Q^{\text {in }}}{V^{\text {br }}}\left(x_{11}^{\text {in }}-x_{11}\right)+r_{11}+u_{b} k_{L} a\left(S_{\mathrm{O}}^{\max }-S_{\mathrm{O}}\right)
$$

where $r_{i}(\boldsymbol{x}), i=1, \ldots, 11$ represents the apparent reaction rate depending on the kinetic rates of degradation of the components, $k_{L} a$ is the oxygen transfer coefficient, and $S_{\mathrm{O}}^{\max }$ is the dissolved oxygen saturation concentration $\left(S_{\mathrm{O}}^{\max }=10 \mathrm{mg} / \mathrm{L}\right)$.

The input $u_{b}$ is a binary sequence switching between 1 and 0 and represents the state of turbines (on/off) that aerate the plant. Without loss of generality, it is assumed that at time $t=0$ the turbines are on.

\subsection{Control Variables}

There are several possible variables that can serve for control: recycle flowrate, sludge extraction flowrate, electrical power of turbines in aerobic mode, etc. Sometimes also influent flowrate can be used - mainly during rainstorm conditions if the sewage system volume can be used to accomodate some extra wastewater. The real manipulated variable that influences the operation of wastewater treatment plants (WWTP), is the sequence of switching times, i.e. times when the turbines switch on/off.

Unfortunately, this control variable does not occur explicitly in the model equations. However, it is possible to normalise the model with respect to time in order to obtain an alternative description where the true manipulated variables occur in the system equations. Let us assume that there are $N_{c}$ cycles within one day consisting of a period of aeration 
followed by a period of non-aeration and let us denote the lengths of the finite time elements by $\Delta t_{1}, \ldots, \Delta t_{2 N_{c}}$. The final time of the simulation/optimisation $T$ is given as

$$
T=\Delta t_{1}+\Delta t_{2}+\cdots+\Delta t_{2 N_{c}}
$$

The aim of the normalisation is to change the time intervals $\Delta t_{1}, \Delta t_{1}+\Delta t_{2}, \ldots, T$ into evenly spaced fixed time intervals $\tau=1 / 2 N_{c}, 2 / 2 N_{c}, \ldots, 1$. This results in the modified system equations

$$
\frac{\mathrm{d} \dot{\boldsymbol{x}}}{\mathrm{d} \tau}=u(\tau) \boldsymbol{f}\left(\boldsymbol{x}, u_{b}\right), \quad \tau \in[0,1]
$$

where $u(\tau)$ is a piece-wise constant sequence of the length $2 N_{c}$ containing the switching times $\Delta t_{1}, \ldots, \Delta t_{2 N_{c}}$.

\section{Definition of the Optimisation Problem}

The main aim of the WWTP plant is to maintain satisfactory concentrations of organics, nitrogen, phosphorus, and other pollutants. According to the new European Union regulations on the effluent of wastewater treatment plants, the maximum concentrations in terms of chemical oxygen demand (COD), biological oxygen demand (BOD), suspended solids $(\mathrm{SS})$, and total nitrogen $\left(\mathrm{TN}=S_{\mathrm{NO}}+S_{\mathrm{NH}}+S_{\mathrm{ND}}\right)$ are given by:

$$
\begin{aligned}
\mathrm{COD}^{\max } & =125 \mathrm{mg} / \mathrm{L} \\
\mathrm{BOD}^{\max } & =25 \mathrm{mg} / \mathrm{L} \\
\mathrm{SS}^{\max } & =35 \mathrm{mg} / \mathrm{L} \\
\mathrm{TN}^{\max } & =10 \mathrm{mg} / \mathrm{L}
\end{aligned}
$$

As it has been investigated in the previous study (Chachuat et al., 2001), the most critical is the total nitrogen constraint since the other constraints are usually satisfied during normal operating conditions for this plant.

The concentration of nitrogen can be influenced by the amount of oxygen diffused by the turbines during the aeration sequences. In most cases, the larger the aeration percentage time, the lower effluent nitrogen concentration can be attained. However, the economic costs dictate to reduce the aeration times.

The usual practice in controlling the nitrogen concentration is to follow some indirect setpoint indicators as for example ammonia concentration, dissolved oxygen, redox potential, nitrogen depletion detection, etc. (Caulet et al., 1998; Debusscher et al., 1999; Lukasse et al., 1999; Spanjers et al., 1996). The selection of the setpoint/controlled variable might be dictated by the sensor availability or process controlability. The actual setpoint value is often chosen from process knowledge, or based on some preliminary experiences.

In this study, we aim at optimisation of the higher level - based on the overall and economic objectives. Therefore, instead of choosing a suitable controlled variable and its setpoint, we directly optimise an economic criterion. 


\subsection{Performance index}

There are several possible choices of the performance index. One of the simplest ways is to minimise the overall nitrogen concentration during the day as

$$
\min _{u} J=\int_{0}^{1} \mathrm{TN}(t) \mathrm{d} t
$$

With such a choice, the nitrogen constraint is automatically satisfied, whenever the plant design and operating conditions make it possible.

In this study, economic cost has been chosen as the most realistic. About 3/4 of the total cost is related to energy consumption of the aeration turbines (Vasel, 1988). As these operate in on/off mode, minimising the time of aeration will decrease the operating costs. Therefore, the dimensionless cost function is defined as

$$
\min _{u} J=\frac{\sum_{j=1}^{N_{c}} u\left(\tau=\frac{2 j-1}{2 N_{c}}\right)}{T}
$$

\subsection{Constraints}

In addition to the quality constraints specified by (8)-(11), some additional limitations are imposed on the aeration times to ensure the feasibility of the computed aeration profiles and to prevent the turbines from damaging.

The minimum air-on and air-off times are set to 15 minutes to avoid too frequent cycling of the turbines and to ensure that the activated sludge after anoxic periods will be sufficiently aerated and mixed in the aeration tank.

Maximum times of 120 minutes are also considered to prevent floc sedimentation in the aeration tank as well as anaerobic conditions, hence modifying the degradation performances. In addition, the CSTR assumption may be violated for extended periods with no agitation.

In order to find a stationary regime, initial conditions of the plant are assumed to be unknown and are subject to optimisation. Then, the requirement of a stationary regime dictates that states at the final optimisation time are the same as the initial states.

The final time of optimisation $T$ has been chosen as one day as the disturbances are periodic with this frequency. This results in an equality constraint that sum of all aeration and non-aeration times should be equal to $T$.

\subsection{Optimisation Problem}

To summarise, the optimisation problem can be stated as follows:

$$
\min _{u, \boldsymbol{p}} J=\frac{\sum_{j=1}^{N_{c}} u\left(\tau=\frac{2 j-1}{2 N_{c}}\right)}{T}
$$


subject to

$$
\begin{aligned}
\frac{\mathrm{d} \dot{\boldsymbol{x}}}{\mathrm{d} \tau} & =u \boldsymbol{f}\left(\boldsymbol{x}, u_{b}\right), \quad \tau \in[0,1], \quad \boldsymbol{x}(0)=\boldsymbol{p} \\
0 & =\|\boldsymbol{x}(1)-\boldsymbol{p}\| \\
T & =\sum_{j=1}^{2 N_{c}} u(j) \\
10 & \geq \mathrm{TN}(\tau)=S_{N O}(\tau)+S_{N H}(\tau)+S_{N D}(\tau) \\
u(j) & \in[15,120] \min , \quad j=1,2 N_{c}
\end{aligned}
$$

There are several possible dynamic optimisation methods that can solve this problem. As the optimised variables are time independent, it is particularly suitable to convert the original dynamic problem into static one. In order to avoid inclusion of integer variables that currently may pose problems and complicate the solution, it is supposed that the number of the cycles $N_{c}$ is known. In this case the problem reduces to nonlinear programming task.

Two popular conversion methods are orthogonal collocation (OC) (Logsdon and Biegler, 1989; Cuthrell and Biegler, 1989) and control vector parameterisation (CVP) (Teo et al., 1991; Fikar et al., 2000). The first one creates large NLP problems as the dynamic state variables are approximated by orthogonal polynomials. On the other hand, it is straightforward to use when state variable inequality constraints (as (18)) are considered. The second group is suitable if the problem comprises a large number of states but involves integration of the differential equations, thus augmenting the computational time considerably.

In this work, CVP approach has been chosen. As optimisation solver, the general purpose dynamic optimisation package DYNO (Fikar and Latifi, 2001) has been employed. Its underlying NLP solver is NLPQL (Schittkowski, 1985), IVP solver can be VODE (Brown et al., 1989) or DASSL (Brenan et al., 1989), and the gradients are calculated from the backward integration of the adjoint variables.

\subsection{State Variable Constraints}

Different approaches to handle state variable inequality constraints are possible within the CVP framework (Teo et al., 1991; Vassiliadis et al., 1994; Feehery and Barton, 1998). We have converted (18) into an endpoint integral equality constraint by the relation

$$
\begin{aligned}
\frac{\mathrm{d} x_{12}}{\mathrm{~d} \tau} & =\max \left(\mathrm{TN}^{\mathrm{max}}-\mathrm{TN}(\tau), 0\right)^{2} \\
x_{12}(1) & =0
\end{aligned}
$$

Note that squaring the max operator ensures first order continuity and improves integration speed. The second equation is often converted into inequality

$$
x_{12}(1) \leq \varepsilon
$$

where $\varepsilon$ is a small positive number to improve NLP convergence. 


\section{Results and Discussion}

The above described techniques that solve inequality state path constraints have been tested and the best results have been obtained with the Max approach (Fikar, 2001). Adding interior point constraints as suggested by Vassiliadis et al. (1994) might produce better results. However, due to the mechanism of calculating the gradients by the system of adjoint variables, each interior constraint generates another system of differential equations. As the number of the constraints is large, this would increase the computational time significantly.

Another possible approach would be to generate the gradients by the method of sensitivities. In that case, the number of constraints does not change the number of differential equations needed to integrate. However, each optimised variable adds another system of differential equations describing the sensitivities. As for the case of the WWTP process, the number of the optimised times is large $\left(2 N_{c}\right)$, the sensitivity method would not decrease the computational burden.

Based on some preliminary experiments (Chachuat, 2001), the number of cycles has been fixed to $N_{c}=29$ and was not a subject of further optimisation as this would lead to mixed integer dynamic optimisation (Barton et al., 2000; Branicky et al., 1998).

This optimisation problem converged to the optimal aeration profile with the average aeration of $39.51 \%$ shown in Fig. 3. It can be noticed that the total nitrogen hits the maximum constraint. The same cost value has been obtained in Chachuat (2001) using fixed initial state conditions and the overal optimisation time $T=60$ days.

It should be noted that CVP approach to dynamic optimisation converges only to a local optimum and the global optimum need not to be found. To reduce this probability, we have performed several optimisations with different starting values of the optimised parameters and different precisions. Although several local optima have been found, the minimum average aeration remainded approximately the same.

From the all 11 states, nitrate and nitrite nitrogen concentration $S_{\mathrm{NO}}$ and dissolved oxygen concentration $S_{\mathrm{O}}$ are plotted in Fig. 4. They are particularly interesting, because on the contrary to other states, only these two show a limited sensitivity towards the disturbances (inlet flowrates and inlet concentrations). More precisely, switching of the turbines in the obtained optimal stationary regime occurs frequently either if the concentration of $S_{\mathrm{NO}}$ falls close to zero or if the concentration of $S_{\mathrm{O}}$ is sufficiently high. Moreover, these two states can be measured. A simple feedback control strategy can then be proposed from their behaviour:

1. Start aeration when $S_{\mathrm{NO}}$ decreases sufficiently close to zero,

2. Stop aeration when $S_{\mathrm{O}}$ reaches a certain value.

We note that the first rule has been proposed for example by Zhao et al. (1994a) for a different alternating WWTP setup (BIO-DENITRO) and based on an analysis of a simplified ASM1 model. This rule follows from the fact that the denitrification period should be large enough to consume most of the $S_{\mathrm{NO}}$ in the reactor. On the other side, it 

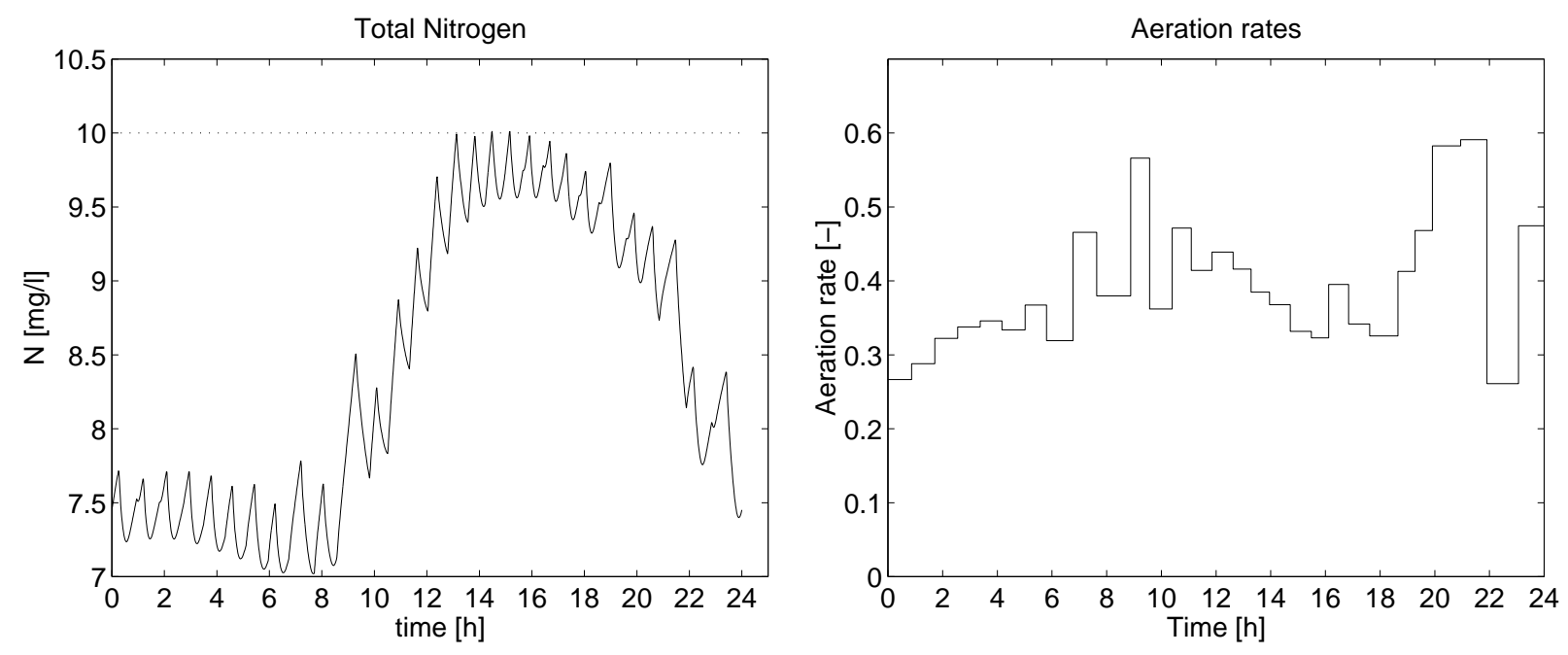

Figure 3: Optimal stationary trajectories for $J=39.51 \%$. Left: Nitrogen constraint, right: aeration policy
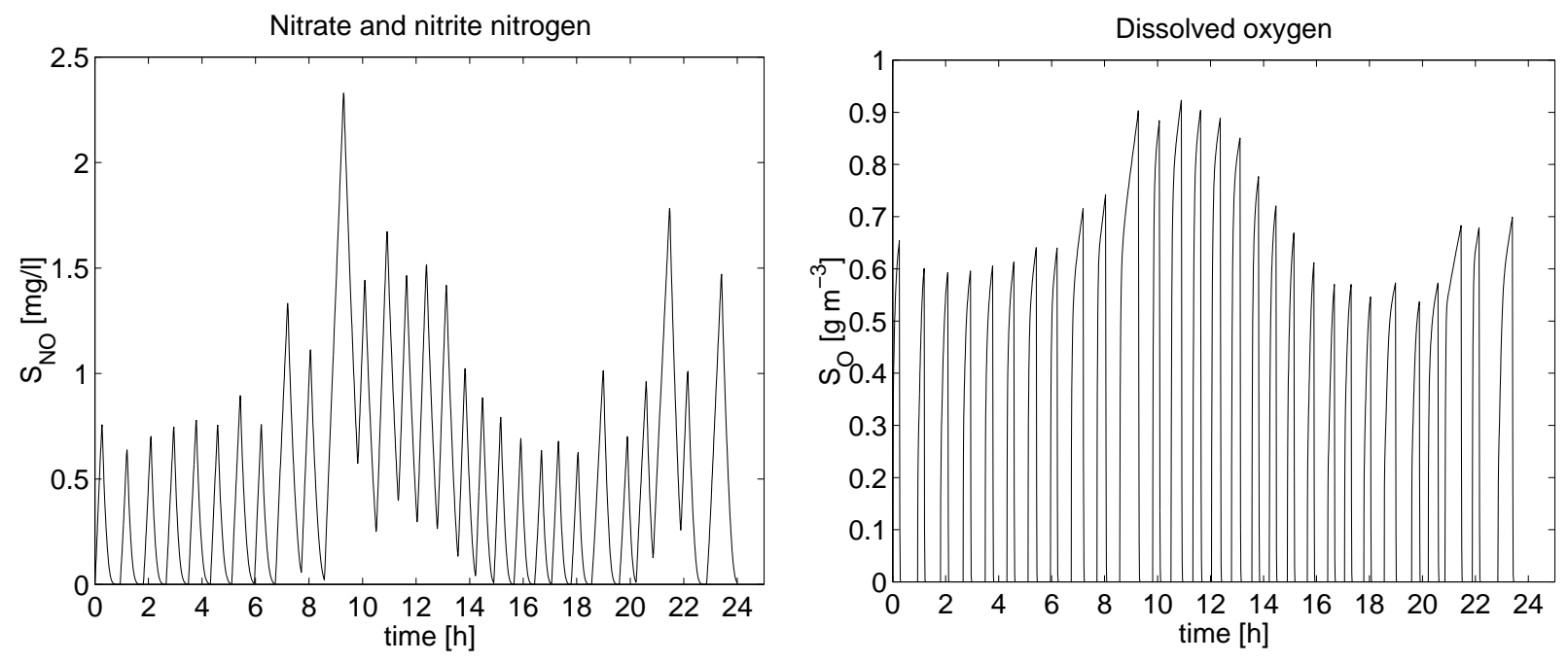

Figure 4: Optimal stationary trajectories for $J=39.51 \%$. Left: Nitrate and nitrite nitrogen, $S_{\mathrm{NO}}$, right: Dissolved oxygen, $S_{\mathrm{O}}$ 

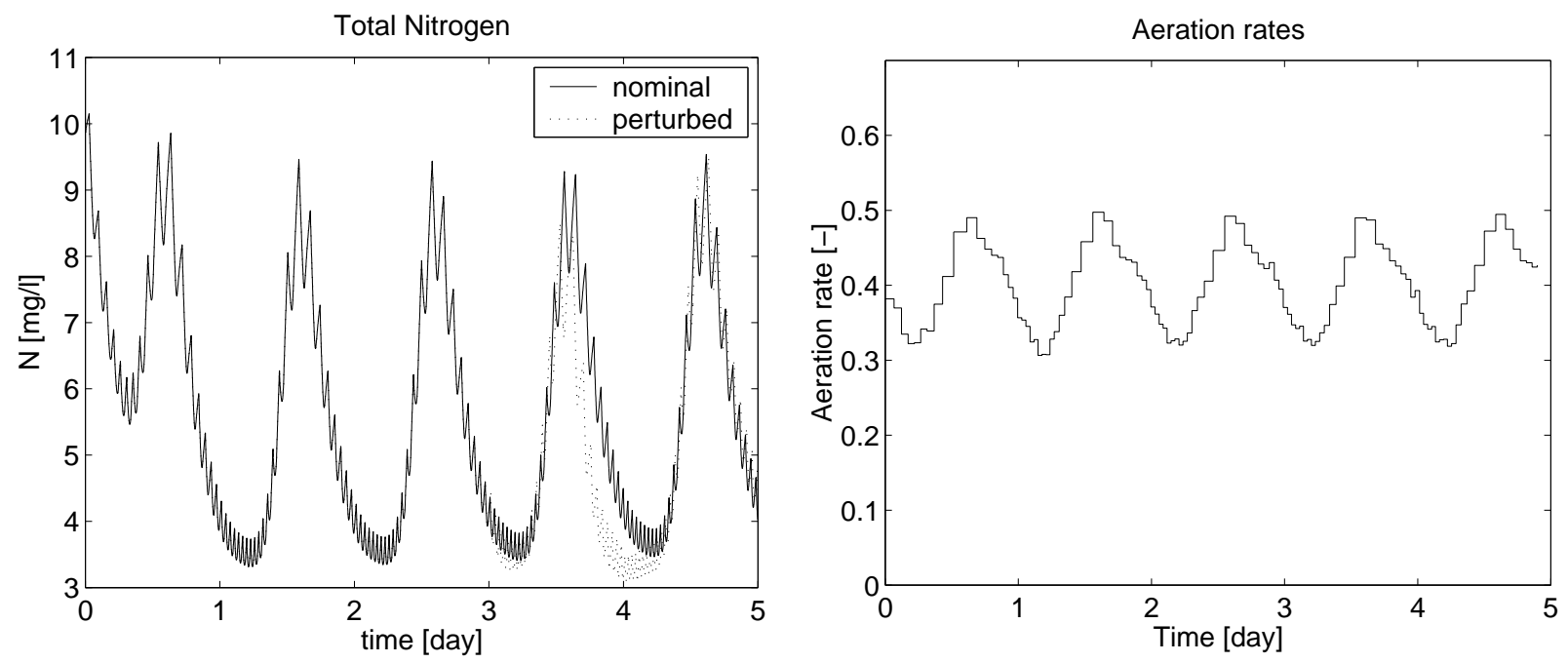

Figure 5: Trajectories for rule based control. Left: Nominal and perturbed nitrogen constraint, right: nominal aeration policy

is not necessary to make it longer if the $S_{\mathrm{NO}}$ concentration is already close to zero as no relevant bioprocess takes place in the reactor.

Also the second rule can be found quite often working well in practice. However, it is not clear what the $S_{\mathrm{O}}$ setpoint should be. Another difficulty arises as the nature of disturbances causes the setpoint to be time-varying. Actually, its shape is in this case similar to that of the influent flowrate.

The application of these simple rules is shown in Fig. 5 where the total nitrogen concentration is shown for two cases. The first one denoted as nominal applies the rules with values of $S_{\mathrm{NO}}(\min )=0.01 \mathrm{mg} / \mathrm{L}$ and $S_{\mathrm{O}}(\max )=0.7 \mathrm{mg} / \mathrm{L}$. In the perturbed case it is supposed that the third day is rainy with $300 \%$ increase of the influent flow and with $50 \%$ decrease of the influent concentrations for the whole day.

It is interesting to note that the simple feedback control policy produces aeration rates that act actively against the disturbances. Continuation of the simulation for another 200 days (not shown here) to attain stationary operation gives the average aeration rate approximately the same as that of the optimal control (39.60\%) with the peak concentration of the total nitrogen only slightly higher $(10.74 \mathrm{mg} / \mathrm{L})$.

Also, the disturbance rejection caused by rainy day simulation is satisfactory. However, as rainy conditions have the largest impact on the settler behaviour that has not been modelled here, the more detailed model may behave differently.

\section{Conclusions}

This paper has dealt with the determination of the optimal aeration strategies for smallsize activated sludge plants based on dynamic optimisation. The model employed for the optimisation is the standard ASM1 model. From the control point of view, this model 
represents a system with one manipulated input - sequence of aeration/non-aeration times and with primary output - total nitrogen concentration in the effluent. No setpoint is known for the output, only its upper constraint.

Based on the problem specifications, the optimisation task has been defined and solved using the dynamic optimisation solver DYNO. The time base for the optimisation has been fixed to one day, based on the periodicity of the disturbances - composition and flowrate of the influent.

To assure stationary operation of the plant, initial states were considered as optimised parameters and a terminal constraint was included that initial and terminal states should be the same.

Based on the optimal stationary state profiles, simple feedback policy has been defined that relates the start and stop of aeration to nitrate and dissolved oxygen levels, respectively. Application of this controller for several days showed only a very small deterioration compared to the dynamic optimisation solution.

The results obtained can serve to several purposes. The dynamic optimisation solution can indicate the relation between the actual and optimum operation and whether there is a room for improvement that will justify additional investments due to necessary sensors needed for state estimation. Next, the stationary profile can be used as a setpoint at the existing plant or the simple rules observed here can be used to enhance the existing operating policies.

\section{Acknowledgments}

This work has been supported by the Ministère de la Recherche et Technologie and Conseil Régional de Lorraine. This financial support is very gratefully acknowledged.

\section{References}

Alex, J., Beteau, J.-F., Copp, J., Hellinga, C., Jeppsson, U., Marsili-Libelli, S., Pons, M.N., Spanjers, H., and Vanhooren, H. (1999). Benchmark for evaluating control strategies in wastewater treatment plants. In Proc. ECC'99. Karlsruhe, Germany.

Barton, P. I., Galán, S., and Banga, J. R. (2000). Optimization of hybrid discrete/continuous dynamic systems. Computers chem. Engng. 24 (4), 851-864.

Branicky, M. S., Borkar, V. S., and Mitter, S. K. (1998). A unified framework for hybrid control: Model and optimal theory. IEEE Trans. Automatic Control 43 (1), 31-45.

Brenan, K. E., Campbell, S. E., and Petzold, L. R. (1989). Numerical Solution of Initial Value Problems in Differential-Algebraic Equations. North-Holland, New York.

Brown, P. N., Byrne, G. D., and Hindmarsh, A. C. (1989). VODE: A variable coefficient ODE solver. SIAM J. Sci. Stat. Comput. 10, $1038-1051$. 
Caulet, P., Lefevre, F., Bujon, B., Réau, P., Philippe, J. P., and Audic, J. M. (1998). Automated aeration management in wastewater treatment: Interest of the application to serial basins configuration. Wat. Sci. Tech. 37 (12), 35-42.

Chachuat, B. (2001). Méthodologie d'optimisation dynamique et de commande optimale des petites stations d'épuration à boues activées. Ph.D. thesis, Institut National Polytechnique de Lorraine.

Chachuat, B., Roche, N., and Latifi, M. A. (2001). Dynamic optimisation of small size wastewater treatment plants including nitrification and denitrification processes. Computers chem. Engng. 25 (4-6), 585-593.

Cuthrell, J. E. and Biegler, L. T. (1989). Simultaneous optimization and solution methods for batch reactor control profiles. Computers chem. Engng. 13 (1/2), 49-62.

Debusscher, D., Vanhooren, H., and Vanrolleghem, P. (1999). Benchmarking two biomass loading control strategies for activated sludge WWTPs. In Proceedings 13th Forum Applied Biotechnology, pages 127-132. Med. Fac. Landbouww. Univ. Gent, 64/5a.

Feehery, W. F. and Barton, P. I. (1998). Dynamic optimization with state variable path constraints. Computers chem. Engng. 22 (9), 1241-1256.

Fikar, M. (2001). On inequality path constraints in dynamic optimisation. Technical Report mf0102, Laboratoire des Sciences du Génie Chimique, CNRS, Nancy, France.

Fikar, M. and Latifi, M. A. (2001). User's guide for FORTRAN dynamic optimisation code DYNO. Technical Report mf0201, LSGC CNRS, Nancy, France; STU Bratislava, Slovak Republic.

Fikar, M., Latifi, M. A., Corriou, J. P., and Creff, Y. (2000). CVP-based optimal control of an industrial depropanizer column. Computers chem. Engng. 24 (2-7), $909-915$.

Henze, M., Grady, C. P. L., Gujer, W., Marais, G. v. R., and Matsuo, T. (1987). Activated Sludge Model No. 1. Technical Report 1, IAWQ, London.

Isaacs, S. (1996). Short horizon control strategies for an alternating activated sludge process. Wat. Sci. Tech. 34 (1-2), 203-212.

Isaacs, S. (1997). Automatic adjustment of cycle length and aeration time for improved nitrogen removal in an alternating activated sludge process. Wat. Sci. Tech. 35 (1), $225-232$.

Kim, H., McAvoy, T. J., Anderson, J. S., and Hao, O. J. (2000). Control of an alternating aerobic-anoxic activated sludge system - Part 2: Optimization using a linearized model. Control Engineering Practice 8 (3), 279-289. 
Lindberg, C.-F. (1998). Multivariable modeling and control of an activated sludge process. Wat. Sci. Tech. 37 (12), 149-156.

Logsdon, J. S. and Biegler, L. T. (1989). Accurate solution of differential-algebraic optimization problem. Ind. Eng. Chem. Res. 28, 1628-1639.

Lukasse, L. J. S., Keesman, K. J., Klapwijk, A., and van Straten, G. (1999). A comparison of NH4/NO3 control strategies for alternating activated sludge processes. Wat. Sci. Tech. 39 (4), 93-102.

Potter, T. G., Koopman, B., and Svoronos, S. A. (1996). Optimization of a periodic biological process for nitrogen removal from wastewater. Wat. Res. 30 (1), 142-152.

Qin, S. J., Martínez, V. M., and Foss, B. A. (1997). An interpolating model predictive control strategy with application to a waste treatment plant. Computers chem. Engng. 21 (S1), S881-S886.

Schittkowski, K. (1985). NLPQL : A FORTRAN subroutine solving constrained nonlinear programming problems. Annals of Operations Research 5, 485-500.

Spanjers, H., Vanrolleghem, P., Olsson, G., and Dold, P. (1996). Respirometry in control of the activated sludge process. Wat. Sci. Tech. 34 (3-4), 117-126.

Teo, K. L., Goh, C. J., and Wong, K. H. (1991). A Unified Computational Approach to Optimal Control Problems. John Wiley and Sons, Inc., New York.

Vasel, J.-L. (1988). Contribution à l'étude des transferts d'oxygène en gestion des eaux. Ph.D. thesis, Fondation Universitaire Luxemourgeoise, Luxembourg, Arlon.

Vassiliadis, V. S., Sargent, R. W. H., and Pantelides, C. C. (1994). Solution of a class of multistage dynamic optimization problems. 1. Problems without path constraints, 2. Problems with path constraints. Ind. Eng. Chem. Res. 33, 2111-2122, 2123-2133.

Zhao, H., Isaacs, S. H., Søeberg, A., and Kümmel, M. (1994a). A novel control strategy for improved nitrogen removal in an alternating activated sludge process - Part I. Process analysis. Wat. Res. 28 (3), 521-534.

Zhao, H., Isaacs, S. H., Søeberg, A., and Kümmel, M. (1994b). A novel control strategy for improved nitrogen removal in an alternating activated sludge process - Part II. Control development. Wat. Res. 28 (3), 535-542.

Zhao, H., Isaacs, S. H., Søeberg, H., and Kümmel, M. (1995). An analysis of nitrogen removal and control strategies in an alternating activated sludge process. Wat. Res. $29(2), 535-544$. 